\title{
COMBINATION ABILITY STUDY OF SEVERAL LINES SYNTHESIZED BY AGROARFA ALBANIA BASED ON THE TEST METHOD
}

\author{
$\operatorname{Artan}_{\text {Sota }{ }^{*}, \text { Fetah Elezi }^{2 *} \text {, Nazmi Hasani }}{ }^{3}$ \\ ${ }^{1 *}$ Agricultural University of Tirana, Faculty of Agronomy and Environment, Department of Plant Production, \\ Tirana, Albania; \\ ${ }^{2 *}$ Agricultural University of Tirana, Institute Plant Genetic Resources, Tirana, Albania; \\ ${ }^{3}$ University of Prishtina, Faculty of Agriculture and Veterinary, Department of Plant Production, Pishtina, Kosovo; \\ *Corresponding author Artan Sota, e-mail: a.sota@arfa.com.al;
}

Received January 2018; Accepted February 2019; Published March 2019;

DOI: https://doi.org/10.31407/ijees9201

UOI license: http://u-o-i.org/1.01/ijees/61275352

\begin{abstract}
Creating new lines and hybrids, with higher production capabilities than existing ones, suitable for particular ecological and agricultural environments, remains a continuing problem ahead of the maize breeding programs. For this purpose, the Genetic Improvement Center, Agroarfa Lushnja, works through a genetic improvement program for maize. The aim is to create hybrids of the 500-600 class, suitable in the irrigated conditions of the coastal area of Albania. This paper presents the testcross data of some inbred lines generated by the self-pollination of the hybrid $32 \mathrm{~F} 73$, it is a late maturing hybrid, but which goes well in the conditions under which the study was conducted. From the F2 population of the 32F73 hybrid were selected the most interesting plants for production indicators and other agronomic traits. Then the plant selection work continued until their phenotypic uniformity reached at the sixth generation of self-pollination (I6). Parallel to this, some of the selected plants of the F2 population of 32F73 hybrid were crossed with some of our best lines (AS2, AS4, AS5, AS8, AS10 and AS13) and continued with selfpollination until they reached the minimum inbred. All the lines created after the selections were crossed with four different tester lines that were AS17, AS19, AS20 and AS23. Their hybrid combinations, obtained from the testcross, line x-tester, were tested in the second year to see the heteroz effect of any hybrid combination, inbred line $\mathrm{x}$ tester. This paper gives the data of hybrid combinations (line $\mathrm{x}$ tester) for two important indicators, yield (kv/ha) and weight of 1,000 kernels ( $\mathrm{g}$ ). If an inbred line represents high combining ability with all tester lines, it means that the line has general combining ability. On the contrary, it can be characterized for specific combining ability. The test was carried out with hybrid combinations of 35 inbred lines of 7 selected groups, crossed with 4 tester lines. From the study, interesting data were obtained from which some combinations are of interest to further work in the genetic improvement programs of maize.
\end{abstract}

Key words: Combining ability, crossing, tester cross 